\title{
The prevalence of antibodies to Toxoplasma gondii in sheep in the Western Cape, South Africa
}

\author{
Authors: \\ Kenneth Hammond-Aryee ${ }^{1}$ \\ Lesley S. van Helden ${ }^{2}$ \\ Paul D. van Helden ${ }^{1}$

\section{Affiliations:} \\ ${ }^{1}$ Division of Molecular \\ Biology and Human \\ Genetics, SA MRC Centre for \\ Tuberculosis Research, DST/ \\ NRF Centre of Excellence for \\ Biomedical and Tuberculosis \\ Research, Stellenbosch \\ University, South Africa \\ ${ }^{2}$ Veterinary Services, \\ Western Cape Government \\ Agriculture, South Africa \\ Correspondence to: \\ Kenneth Hammond-Aryee \\ Email: \\ kenhammond@sun.ac.za
}

Postal address:

PO Box 241, Tygerberg 8000

South Africa

\section{Dates:}

Received: 01 June 2015

Accepted: 26 Aug. 2015

Published: 03 Nov. 2015

How to cite this article: Hammond-Aryee, K., Van Helden, L.S. \& Van Helden, P.D., 2015, 'The prevalence of antibodies to Toxoplasma gondii in sheep in the Western Cape, South Africa', Onderstepoort Journal of Veterinary Research 82(1), Art. \#993, 5 pages. http:// dx.doi.org/10.4102/ojvr. v82i1.993

\section{Copyright:}

(C) 2015. The Authors. Licensee: AOSIS OpenJournals. This work is licensed under the Creative Commons Attribution License.

Read online:
The seroprevalence of Toxoplasma gondii antibodies in a sample of 292 merino sheep farmed in a semi-intensive manner in the Overberg region of the Western Cape, South Africa, was investigated. Antibody seroprevalence was determined by enzyme-linked immunosorbent assay. Of the total sample, 23 sheep tested positive for T. gondii antibodies (8\%; 95\% CI: 4.768810.9846). There was no statistically significant relationship between seroprevalence and age of the sheep. The highest seroprevalence was found in sheep between 28 and 40 months old; a total of 19 sheep were seropositive by 40 months. No seropositive sheep were found in the age group between 16 and 28 months. The seroprevalence reported in this study is higher than what has previously been reported for the Western Cape $(6 \%)$ and across South Africa on average $(4.7 \%)$. As sheep farming is economically significant in South Africa, the presence of T. gondii amongst sheep may pose a production threat to the small-stock industry as well as to public health and food security. We therefore recommend further surveillance to identify high-risk animal populations so that local control measures can be put in place.

\section{Introduction}

Toxoplasma gondii is an apicomplexan, obligate intracellular protozoan parasite of global importance. T. gondii infection causes the disease toxoplasmosis in humans and animals and its antibodies are known to be present in about a third of the global human population, although local and regional prevalences vary widely. Toxoplasma gondii is very successful as a pathogen owing to its ability to infect almost all mammals and birds (Dubey 2002). Toxoplasmosis is found worldwide, but is more common at lower altitudes and in warm and humid climates.

Members of the family Felidae are the only known definitive hosts for T. gondii. Cats can become infected by feeding on prey already infected with dormant $T$. gondii cysts or tachyzoites and also by drinking oocyst-contaminated water. Infected cats are known to shed infective oocysts in their faeces 5-12 days post ingestion of oocysts (Al Kappany et al. 2010; Dubey 1995; Elmore et al. 2010), thereby contaminating the environment and posing a risk of transmission to other species.

Toxoplasmosis causes substantial economic losses in sheep farming globally and was first described in ovines in 1954 (Buxton et al. 2007; Jones \& Dubey 2012). Primary T. gondii infections in livestock, in particular sheep and goats, pose a health risk to these animals, as infection is known to cause abortions, stillbirths and neonatal mortalities. In the United Kingdom, for example, ovine toxoplasmosis causes up to $2 \%$ of foetal losses per annum (Buxton et al. 2007; Innes et al. 2009).

In humans and animals, T. gondii infections are acquired post natally by the ingestion of tissue cysts in partially cooked meat, infective oocysts in food or water contaminated with infected felid faeces, or handling of tissues of animals infected with tissue cysts. Infection can also occur by vertical transmission from mother to foetus in humans, sheep, goats and small rodents (Hill \& Dubey 2002; Jones \& Dubey 2012; Smith 1993). In humans, infection can also occur via blood transfusions and organ transplantation, although this is rare. Infection has been known to occur via inhalation of aerosols containing infective oocysts or from contact with contaminated soils in both humans and animals.

In sheep, T. gondii infection is mainly acquired post natally, as congenital infections usually lead to abortions. Rarely, congenitally affected lambs are born, which can be a possible route for infection in humans (Dubey \& Welcome 1988; Williams et al. 2005).

There are various risk factors reported to be associated with $T$. gondii infection in sheep. Seroprevalence in sheep is known to increase with age and is therefore higher in ewes or rams than in lambs (Dubey 2009). Other risk factors for T. gondii infection in sheep include the presence 
of cats on farms, the nature of farming and management practices (commercial vs non-commercial; intensive, semiintensive, free range or open), climatic conditions and geographic location, presence of surface drinking water sources and size of the farm (Abu Samra et al. 2007; Andrade et al. 2013; Mainar et al. 1996). Although infected ewes do not always show symptoms of clinical toxoplasmosis, T. gondii infection has been noted as an important cause of ovine abortions in the United States and Europe (Dubey 2009), with seroprevalence in sheep ranging from 20.8\% (Huffman et al. 1981) to $73.8 \%$ (Dubey \& Welcome 1988) in the United States. It has also been suggested that some breeds of sheep may be more susceptible to T. gondii infection than others (Dubey \& Welcome 1988; Williams et al. 2005).

In South Africa, seroprevalence studies have been reported in human populations (both asymptomatic and HIV and/or AIDS cohorts) as well as in animal populations, as reviewed by Hammond-Aryee, Esser and Van Helden (2014a). However, these studies are limited and few of them are from the post-HIV era. There have been even fewer studies in animal populations and only one focused on sheep, reporting seroprevalence as $4.3 \%$ via enzyme-linked immunosorbent assay (ELISA) and 5.6\% via indirect fluorescent antibody (IFA) tests (Abu Samra et al. 2007). In that study, the Western Cape was also mentioned as the province with the highest consumption of mutton in South Africa.

The ingestion of partially cooked, undercooked or raw meat has been documented as a significant mode of T. gondii infection worldwide. Studies in Europe have shown that ingestion of undercooked lamb was a risk factor in the acquisition of $T$. gondii infection in a cohort of pregnant women (Cook et al. 2000). In a US study, $50 \%$ of a cohort of 131 women who had vertically transmitted T. gondii to their infants recalled having eaten raw or uncooked mutton sometime during their pregnancies (Boyer et al. 2005). As T. gondii can be transmitted to humans by the ingestion of mutton or lamb, sheep may have an important role in the epidemiology of toxoplasmosis. Investigation into the presence or absence of $T$. gondii antibodies in a population of sheep will provide significant insight into the risk of toxoplasmosis in a particular ecosystem.

The current study focused on the seroprevalence of T. gondii antibodies in a flock of sheep in South Africa. It contributes to the knowledge about this important pathogen and the role of animals in the epidemiology of toxoplasmosis.

\section{Materials and methods Study area and climate}

Sheep were sampled from a farming area in Bredasdorp in the Overberg region of the Western Cape, South Africa. The area has a Mediterranean climate and receives about $350 \mathrm{~mm}$ of rain per year, most of which is in winter. December is usually associated with the lowest rainfall $(<20 \mathrm{~mm})$, whereas August is associated with the highest rainfall $(40 \mathrm{~mm}-50 \mathrm{~mm})$. The

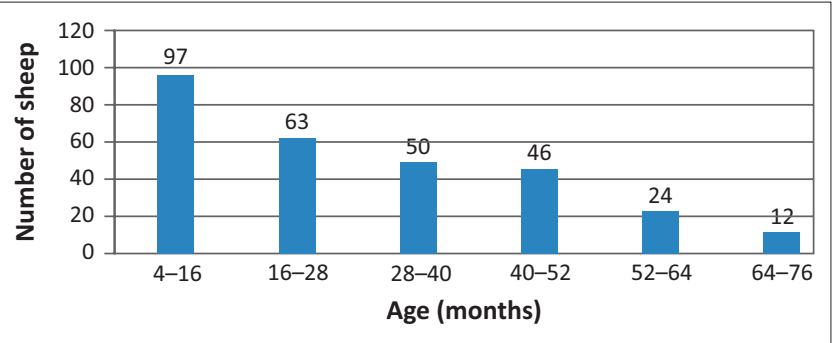

FIGURE 1: Age distribution of study sample.

average midday temperatures are between $17.5^{\circ} \mathrm{C}$ in winter and $26.2^{\circ} \mathrm{C}$ in summer. Livestock farmed in the region include mostly sheep and cattle.

The sample consisted of 292 merino sheep (4 rams and 288 ewes) selected randomly from a flock of approximately 1000 1500. The sheep were farmed in a semi-intensive manner, grazing planted pastures and crop stubble. The rams were between 16 and 64 months old, whilst the ewes were between 4 and 76 months old, with the modal age group being between 4 and 16 months (Figure 1).

\section{Cat presence on the farm}

At the time of sampling, there were 10 domestic cats living on the farm.

\section{Blood collection}

In May 2014, blood samples were collected from the 292 sheep via venipuncture. Blood was collected into anticoagulantcontaining tubes and immediately put on ice, after which it was transported to our laboratories and centrifuged at $3500 \mathrm{~g}$ for $5 \mathrm{~min}$ to isolate the plasma. The plasma was then stored at $-80^{\circ} \mathrm{C}$ for further analysis.

\section{Serological investigations}

An ELISA was used for the detection of IgG antibodies to $T$. gondii in sheep plasma samples. The ELISA test was performed via a commercially available enzyme immunoassay kit (IDEXX Toxotest Ab, IDEXX Laboratories, Switzerland) according to the manufacturer's instructions.

Briefly, thawed sheep plasma samples and controls were diluted at a ratio of 1:400 in wash buffer to prevent nonspecific reactions. The diluted plasma samples were then dispensed into microtitre plates precoated with inactivated T. gondii antigen and mixed by gentle shaking.

The microplate was covered with an adhesive plate cover and incubated at $37{ }^{\circ} \mathrm{C}$ for $60 \mathrm{~min}$. Each well was then washed three times with approximately $300 \mathrm{~mL}$ buffer in each wash. All residual wash solution was removed by tapping the microplate gently onto an absorbent material. Bound antigenantibody complexes were then conjugated with $100 \mu \mathrm{L}$ peroxidase-labelled anti-ruminant IgG conjugate. The plate was covered and incubated at $37^{\circ} \mathrm{C}$ for $60 \mathrm{~min}$. The described wash step was repeated to eliminate any residual unbound 
complexes. Enzyme-bound complexes were visualised by adding $100 \mu \mathrm{L}$ enzyme substrate to the wells and incubating the plate at $26^{\circ} \mathrm{C}$ for $15 \mathrm{~min}$. The enzyme-substrate reaction was stopped by adding $100 \mu \mathrm{L}$ stop solution to each well of the microplate. The absorbance was read on a photometer at a wavelength of $450 \mathrm{~nm}$.

Positive and negative controls provided in the kit were included on each microplate per batch of test samples.

The optical densities of the positive control $(P C x)$ and the samples $\left(\right.$ Sample $\left._{450}\right)$ were corrected by subtracting the optical density of the negative control $(N C x)$. The samples were analysed relative to the positive and negative controls:

$S / P(\%)=100 \times \frac{\text { Sample }_{450}-N C x}{P C x-N C x}$

$\mathrm{S} / \mathrm{P}$ is a ratio of the corrected optical density of the sample to the corrected optical density of the positive control for each sample.

\section{Statistical analysis}

A Pearson chi square test was performed using SAS/STAT statistical analysis software (version 9.3). Correlations between the serological status of sheep and their age were investigated. Differences were deemed statistically significant if $P \leq 0.05$.

\section{Ethical considerations}

Ethical clearance for this study was obtained from the Animal Health Research Ethics Committee of the Western Cape Department of Agriculture (ethical clearance certificate G13/89).

\section{Results}

Of the total sample, 23 sheep (8\%; 95\% CI: 4.7688-10.9846) tested positive for $T$. gondii antibodies.

Figure 2 shows that distinct $T$. gondii antibody seroprevalence patterns were evident in the different age categories shown in Figure 1.

The highest seroprevalence (34\%) was observed in animals between 28 and 40 months old, followed by a seroprevalence of $16.7 \%$ in the $64-76$-month-old group. The seroprevalence in the 52-64-month-old group was $4.2 \%$, whereas a seroprevalence of $2.1 \%$ was seen in both the 4-16-monthold group and the 40-52-month-old group. No seropositive sheep were observed in the 16-28-month-old group.

\section{Discussion}

Infectious diseases, such as toxoplasmosis, have a substantial impact on animal productivity in sheepfarming regions of the world and some may remain undetected in flocks for prolonged periods, leading to unforeseen and unexplained abortions, foetal or newborn

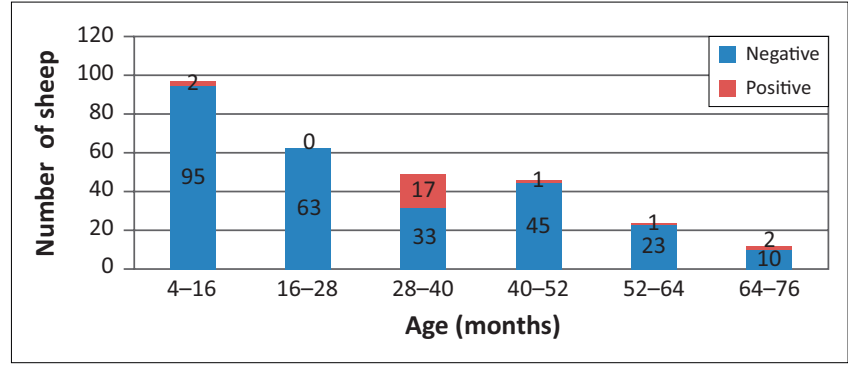

FIGURE 2: Seroprevalence of Toxoplasma gondii antibodies in a sample of sheep, organised according to age.

deaths and infertility. In some cases, these diseases lead to persistent or recurring infection in herds, resulting in poor reproductive output in the long term. Reproductive losses resulting from these diseases are a threat to the long-term economic viability of such flocks.

Toxoplasma gondii antibodies have been detected in naturally exposed sheep flocks worldwide. Reported seroprevalence varies from as low as 3\% in Pakistan (Zaki 1995) to as high as $68 \%$ (Deconinck et al. 1996) in the Ivory Coast and 95.7\% in Turkey (Mor \& Arslan 2007).

Toxoplasma gondii seroprevalence in small ruminants has been reported from some parts of Africa. Hove, Lind and Mukaratirwa (2005) reported a seroprevalence of $67.9 \%$ in a population of sheep and goats from different parts of Zimbabwe. They also reported an eightfold difference in seroprevalence between sheep from a large commercial farm $(10 \%)$ and sheep reared under a communal grazing system (80\%), reporting the presence of many domestic cats and a high household density as potential risk factors for T. gondii infection. In Botswana, seroprevalences of between 10\% (Binta et al. 1998) and 30\% (Sharma et al. 2003) have been reported in a population of goats. In Ghana, Van der Puije et al. (2000) reported a seroprevalence of 33.2\% in sheep and $26.8 \%$ in goats, with a higher seroprevalence reported in female animals $(35.8 \%)$ than in male animals $(21.1 \%)$. Significant differences in seroprevalence were found between breeds, age groups and ecological zones from which the animals were sampled. In Uganda, Bisson et al. (2000) reported a seroprevalence of $31 \%$ in a population of goats, with significantly higher seroprevalence in goats from urban areas than from rural areas. A strong positive correlation was demonstrated between age and seroprevalence.

In South Africa, Abu Samra et al. (2007) reported a seroprevalence of $5.6 \%$ using an IFA test and $4.3 \%$ according to an ELISA. The mean seroprevalence in the Western Cape, as determined by ELISA, was 6\%. The authors also reported a significantly higher seroprevalence in sheep from commercial farms than in sheep from rural or informal-sector farms. A significant correlation was found between seroprevalence and the average minimum temperature. Sheep that were managed in an extensive manner had a significantly lower seroprevalence (1.8\%) than those managed in a semi-intensive or fully intensive system (5.3\%). 
The seroprevalence reported from the current study $(8 \%)$ is higher than the mean provincial seroprevalence reported by Abu Samra et al. (2007). This may be a result of the farm from which the sample was selected being a commercial farm with semi-intensive management, as both of these factors have been shown to contribute to increased risk for seroprevalence.

Most seropositive sheep had acquired the infection by 4 years of age. Seroprevalence is known to increase with age, with $95 \%$ of susceptible ewes seroconverting by 6 years of age (Dubey 2009). In our study, the highest number of seropositive sheep was between 28 and 40 months old; there was no significant relationship between seroprevalence and age of the sheep. These observations may be due to the sample being a convenience sample over which the investigator had no control.

\section{Conclusion}

Transmission of T. gondii to humans and non-food animals is likely to be proportional to the $T$. gondii seroprevalence within food animal populations. There is a need to actively survey at-risk populations such as feral cats, wildlife and food animals within the ecosystem to design appropriate interventions for managing and preventing disease transmission. In Africa, where poverty, poor hygiene and a high burden of HIV infection exist, T. gondii infection is likely to have substantial implications for the health and economic well-being of the people of this continent (Hammond-Aryee, Esser \& Van Helden 2014b).

The seroprevalence reported in this study is higher than the previously reported figures for the Western Cape (6\%) and overall in South Africa (4.7\%) (Abu Samra et al. 2007). Our study was more limited than the comparative study, but our results do suggest ongoing transmission of $T$. gondii in livestock. Cats on sheep farms may be a major risk factor for transmission of $T$. gondii to livestock, as suggested by a recent study in which T. gondii anti-IgG antibody seroprevalence amongst feral cats was found to be $37.1 \%$ (Hammond-Aryee et al. in press).

In South Africa sheep are farmed not only for meat production but also for the production of wool. An infectious disease such as toxoplasmosis can therefore have both health and economic implications in the country. We recommend ongoing surveillance to identify high-risk animal populations so that local control measures can be put in place to prevent interspecies spread of the disease.

\section{Acknowledgements}

The authors acknowledge financial support from the South African Medical Research Council: Centre for Tuberculosis Research, Department of Science and Technology/National Research Foundation Centre of Excellence for Biomedical Tuberculosis Research, Division of Molecular Biology and Human Genetics at the Faculty of Medicine and Health Sciences, Stellenbosch University.

\section{Competing interests}

The authors declare that they have no financial or personal relationships that may have inappropriately influenced them in writing this article.

\section{Authors' contributions}

P.D.v.H. (Stellenbosch University), L.S.v.H. (Western Cape Government Agriculture) and K.H-A. (Stellenbosch University) were responsible for project design. K.H-A. conducted the serological investigation and drafted the manuscript. All authors contributed to editing the manuscript to its final form in preparation for publication.

\section{References}

Abu Samra, N.A., McCrindle, C.M.E., Penzhorn, B.L. \& Cenci-Goga, B., 2007 'Seroprevalence of toxoplasmosis in sheep in South Africa', Journal of the South African Veterinary Association 78(3), 116-120. PMID: 18237032.

Al Kappany, Y.M., Rajendran, C., Ferreira, L.R., Kwok, O.C.H., Abu-Elwafa, S.A., Hilali, M. et al., 2010, 'High prevalence of toxoplasmosis in cats from Egypt: Isolation of viable Toxoplasma gondii, tissue distribution, and isolate designation', Journal of Parasitology 96(6), 1115-1118. PMID: 21158619, http://dx.doi.org/10.1645/ of Parasito 2554.1

Andrade, M.M.C., Carneiro, M., Medeiros, A.D., Neto, V.A. \& Vitor, R.W.A., 2013, 'Seroprevalence and risk factors associated with ovine toxoplasmosis in northeast Brazil', Parasite 20, 20. PMID: 23707895, http://dx.doi.org/10.1051/parasite/2013019

Binta, M.G., Mushi, E.Z., Raborokgwe, M. \& Ndebele, T.R., 1998, 'The prevalence of antibodies to Toxoplasma gondii in goats with history of abortion', Zimbabwe Veterinary Journal 29, 47-50.

Bisson, A., Maley, S., Rubaire-Akiiki, C.M. \& Wastling, J.M., 2000, 'The seroprevalence of antibodies to Toxoplasma gondii in domestic goats in Uganda', Acta Tropica 76(1) 33-38. PMID: 10913763, http://dx.doi.org/10.1016/S0001-706X(00)00086-3

Boyer, K.M., Holfels, E., Roizen, N., Swisher, C., Mack, D., Remington, J. et al., 2005, 'Risk factors for Toxoplasma gondii infection in mothers of infants with congenital toxoplasmosis: Implications for prenatal management and screening', American Journal of Obstetrics and Gynecology 192(2), 564-571. PMID: 15696004.

Buxton, D., Maley, S.W., Wright, S.E., Rodger, S., Bartley, P. \& Innes, E.A., 2007, 'Toxoplasma gondii and ovine toxoplasmosis: New aspects of an old story', Veterinary Parasitology 149(1-2), 25-28. PMID: 17686585, http://dx.doi. org/10.1016/j.vetpar.2007.07.003

Cook, A.J.C., Gilbert, R.E., Buffolano, W., Zufferey, J., Petersen, E., Jenum, P.A. et al., 2000 , 'Sources of Toxoplasma gondii infection in pregnant women: European
multicentre case-control study commentary: Congenital toxoplasmosis-Further thought for food', British Medical Journal 321(7254), 142-147.

Deconinck, P., Pangui, L.J., Akakpo, J., Garrouste, A., Ouattara, L., Roger, F. et al., 1996 'Sero-epidemiology of toxoplasmosis in sheep and goats from Africa', Revue de Médécine Véterinaire 147(5), 377-378.

Dubey, J.P., 1995, 'Duration of immunity to shedding of Toxoplasma gondii oocysts by cats', Journal of Parasitology 81(3), 410-415. PMID: 7776126, http://dx.doi. org/10.2307/3283823

Dubey, J.P., 2002, 'A review of toxoplasmosis in wild birds', Veterinary Parasitology 106(2), 121-153. PMID: 12031816, http://dx.doi.org/10.1016/S0304-4017(02)00034-1

Dubey, J.P., 2009, 'Toxoplasmosis in sheep-The last 20 years', Veterinary Parasitology 163(1-2), 1-14. PMID: 19395175, http://dx.doi.org/10.1016/j.vetpar.2009.02.026

Dubey, J.P. \& Welcome, F.L., 1988, 'Toxoplasma gondii-induced abortion in sheep', Journal of the American Veterinary Medical Association 193(6), 697-700. PMID: 3192448.

Elmore, S.A., Jones, J.L., Conrad, P.A., Patton, S., Lindsay, D.S. \& Dubey, J.P., 2010 'Toxoplasma gondii: Epidemiology, feline clinical aspects, and prevention', Trends in Parasitology 26(4), 190-196. PMID: 20202907, http://dx.doi.org/10.1016/j. pt.2010.01.009

Hammond-Aryee, K., Esser, M. \& Van Helden, P.D., 2014a 'Toxoplasma gondii seroprevalence studies on humans and animals in Africa', South African Family Practice Journal 56(2), 119-124. http://dx.doi.org/10.1080/20786204.2014.108 55349

Hammond-Aryee, K., Esser, M. \& Van Helden, P.D., 2014b, 'Toxoplasmosis in South Africa - Old disease in a new context', Journal of Natural Sciences Research 4(22), 101-105.

Hammond-Aryee, K., Esser, M., Van Helden, L. \& Van Helden, P.D., in press, 'A high seroprevalence of Toxoplasma gondii antibodies in a population of feral cats in the Western Cape province of South Africa', Southern African Journal of Infectious Diseases.

Hill, D. \& Dubey, J.P., 2002, 'Toxoplasma gondii: Transmission, diagnosis and prevention', Clinical Microbiology and Infection Diseases 8(10), 634-640. PMID 12390281, http://dx.doi.org/10.1046/j.1469-0691.2002.00485.x

Hove, T., Lind, P. \& Mukaratirwa, S., 2005, 'Seroprevalence of Toxoplasma gondi infection in goats and sheep in Zimbabwe', Onderstepoort Journal of Veterinary Research 72(4), 267-272. PMID: 16562728. 
Huffman, E.M., Kirk, J.H., Winward, L. \& Gorham, J.R., 1981, 'Relationship of neonatal mortality in lambs to serologic status of the ewe for Toxoplasma gondii', Journal of the American Veterinary Medical Association 178(7), 679-682. PMID: 7204246.

Innes, E.A., Bartley, P.M., Maley, S., Katzer, F. \& Buxton, D., 2009, 'Veterinary vaccines against Toxoplasma gondii', Memórias do Instituto Oswaldo Cruz 104(2), 246-251. PMID: 19430650, http://dx.doi.org/10.1590/S0074-02762009000200018

Jones, J.L. \& Dubey, J.P., 2012, 'Foodborne toxoplasmosis', Clinical Infectious Diseases 55(6), 845-851. PMID: 22618566, http://dx.doi.org/10.1093/cid/ cis508

Mainar, R.C, De la Cruz, C., Asensio, A., Domínguez, L. \& Vázquez-Boland, J.A., 1996 'Prevalence of agglutinating antibodies to Toxoplasma gondii in small ruminants of the Madrid region, Spain, and identification of factors influencing seropositivity by multivariate analysis', Veterinary Research Communications 20(2), 153-159. PMID: 8711895, http://dx.doi.org/10.1007/BF00385636

Mor, N. \& Arslan, M.O., 2007, 'Kars yoresindeki koyunlarda Toxoplasma gondii nin seroprevalansi', Kafkas Üniversitesi Veteriner Fakültesi Dergisi 13(2), 165-170. $\mathrm{http}: / / \mathrm{dx}$.doi.org/10.9775/kvfd.2007.33-A
Sharma, S.P., Baipoledi, E.K., Nyange, J.F.C. \& Tlagae, L., 2003, 'Isolation of Toxoplasma gondii from goats with history of reproductive disorders and the prevalence of
toxoplasma and chlamydial antibodies', Onderstepoort Journal of Veterinary Research 70(1), 65-68. PMID: 12825682.

Smith, J.L., 1993, 'Documented outbreaks of toxoplasmosis: Transmission of Toxoplasma gondii to humans', Journal of Food Protection 56(7), 630-639.

Van der Puije, W.N., Bosompem, K.M., Canacoo, E.A., Wastling, J.M. \& Akanmori, B.D., 2000, 'The prevalence of anti-Toxoplasma gondii antibodies in Ghanaian sheep and goats', Acta Tropica 76(1), 21-26. PMID: 10913761, http://dx.doi. org/10.1016/S0001-706X(00)00084-X

Williams, R.H., Morley, E.K., Hughes, J.M., Duncanson, P., Terry, R.S., Smith, J.E. et al. 2005, 'High levels of congenital transmission of Toxoplasma gondii in longitudinal and cross-sectional studies on sheep farms provides evidence of vertical transmission in ovine hosts', Parasitology 130(3), 301-307. PMID: 15796013 http://dx.doi.org/10.1017/S0031182004006614

Zaki, M., 1995, 'Seroprevalence of Toxoplasma gondii in domestic animals in Pakistan', Journal of the Pakistan Medical Association 45(1), 4-5. PMID: 7731085. 